\title{
Virtual Instrumentation Design on Earthquake Simulation System
}

\author{
Kai-Chao YAO \\ Department of Industrial Education and Technology \\ National Changhua University of Education, No.2, Shi-Da \\ Road \\ Changhua City 50007, Taiwan, R.O.C
}

\section{Wei-Tzer HUANG}

Department of Industrial Education and Technology

National Changhua University of Education, No.2, Shi-Da

Road

Changhua City 50007, Taiwan, R.O.C

\author{
Cheng-Lung LIN \\ Department of Industrial Education and Technology \\ National Changhua University of Education, No.2, Shi-Da \\ Road \\ Changhua City 50007, Taiwan, R.O.C
}

\author{
Pei-En WU \\ Department of Industrial Education and Technology \\ National Changhua University of Education, No.2, Shi-Da \\ Road \\ Changhua City 50007, Taiwan, R.O.C
}

\author{
Jiunn-Shean CHIANG \\ Department of Mechanical Engineering \\ Hsiuping University of Science and Technology, No.11 Gongye Rd, Dali Dist. \\ Taichung City 412-80, Taiwan, R.O.C
}

\begin{abstract}
This research develops a virtual instrumentation on earthquake simulation system. The hardware part, an earthquake simulation platform, is constructed and installed with accelerometers. The software part, LabVIEW, is programmed to record, monitor, and display the p-wave data. LabVIEW is a graphical language of which it is easy operated and designed with friendly human machine interface. In the system design, the various earthquake simulations are generated by adjusting the PWM signals of DC GEAR MOTORS. The signals of earthquake are measured by three-axis-accelerometers. The developed system uses MyDAQ as interface between the control computer and simulation platform. MyDAQ is a data acquisition device that provides the function to measure and analyze live signals anytime. This research completed platform and the software design of earthquake simulation system.
\end{abstract}

Keywords-LabVIEW; earthquake; accelerometer; simulation

\section{INTRODUCTION}

Taiwan is located at circum-Pacific seismic belt that is between Eurasian Plate and Philippine Sea Plate. The circum-Pacific seismic belt is the major cause of earthquakes. Taiwan has various kinds of ground. In the meantime, the architectural designs have to consider the building strength. When earthquakes happened, energy was released and diffused from hypocenter. If you close to the hypocenter, you felt strong vibration. On the other hand, if you leave the hypocenter, you don't feel strong vibration because it's decreased in energy by frictional effects. Through experiments, the motor is turned from low to high-cycle; we see that the accelerations sense speed from slow to fast. Especially, when the frequency of building is same as a cycle of acceleration, energy would harm the building. After a large scale of earthquake occur, the surface is often broken. From the view of energy release, the faults always released to energy in the place. The earthquakes divided into three categories, the first is structural earthquake, the second is eruption earthquake, and the last is impact earthquake. The major result of structural earthquakes causes plate movement and makes diastrophism. Inside the earth has stress energy to push and change the rock formation. As rock formation receives a large of stress energy, the diastrophism which release energy and produce the elastic wave is occurred. The elastic wave is earthquake wave that arrived to earth's surface. It makes a large of shock which is called earthquake. The elastic wave divided into two categories, one is p-wave and the other is s-wave. The p-wave is called pressure wave which is consistent with the direction of motion and the direction of energy movement, and its speed is the fastest. The s-wave is called shear wave which is perpendicular to the direction of motion and the direction of energy movement, and its speed is second. Figure 1 shows the direction of seismic motion.

P-wave

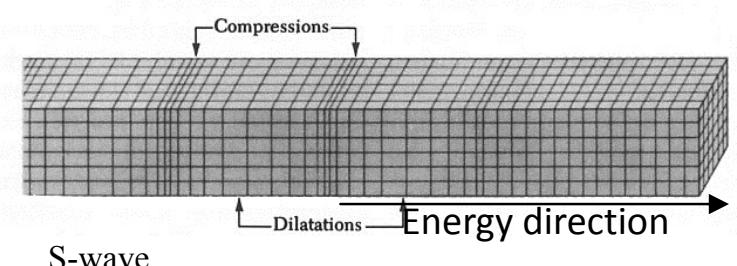

S-wave 


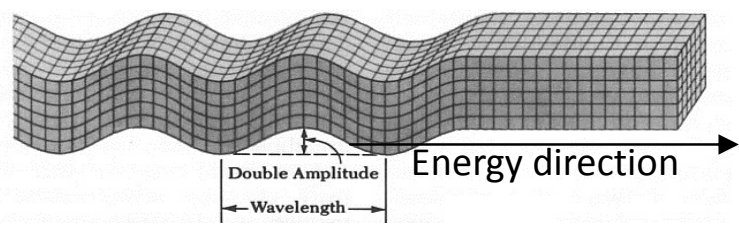

FIGURE I. DIRECTION OF SEISMIC MOTION.

The disturbance which comes from the seismic origin spread as elastic waves form the earth interior to the earth surface and generate body waves and surface waves. If the decay and diffusion of earthquake wave are not considered, the earth surface vibration which is generated by $\mathrm{P}$-wave causes vertical seismic waves first, then $\mathrm{S}$-wave causes horizontal seismic waves, and finally the surface waves appear. The energy of the seismic waves disperses into space, so the farther the seismic waves spread out, the energy per unit volume less. And the vibration is bigger when it is closer to hypocenter. On the other hand, the energy of seismic wave decreases due to the friction force, so it decreased more when the seismic waves spread long, and P-wave decreases most. The vertical seismic waves shake obvious on surface when shallow earthquake happened, and it is inappreciable when deep earthquake happened due to the decrease.

Accelerometer is a device which measure the acceleration. It actuates by itself instead of remote sensor, and it measures the acceleration of earthquake simulation. MMA7361LC, three-axis accelerometer, is taken in this research. MMA7361LC is low-power and thin-capacitive accelerometer, and it has signal adjustment, temperature compensation, and selective sensitivity $( \pm 1.5 \mathrm{~g}$ 和 $\pm 6 \mathrm{~g})$. The acceleration of $\mathrm{XYZ}$ axis could be transferred as numerical data by MMA7361LC. Table 1 shows the g-Select Pin Description, The g-Select feature allows for the selection between two sensitivities.

TABLE I. G-SELECT PIN DESCRIPTION.

\begin{tabular}{|c|c|c|}
\hline g-Select & g-Range & Sensitivity \\
\hline 0 & $1.5 \mathrm{~g}$ & $800 \mathrm{mV} / \mathrm{g}$ \\
\hline 1 & $6 \mathrm{~g}$ & $200 \mathrm{mV} / \mathrm{g}$ \\
\hline
\end{tabular}

The relation between earthquake intensity and acceleration is explained by the psychologist Weber-Fechner: When the level of stimulation (acceleration, $\alpha \mathrm{I}$, unit: $\mathrm{cm} / \mathrm{s} 2$ ) increases as Geometric progression, the level of sense (intensity, I) increases as arithmetic progression.

$$
\log \alpha_{\mathrm{I}}=(\mathrm{I} / 2)-0.6
$$

\section{SYSTEM STRUCTURE}

The earthquake simulation platform uses NI MyDAQ as interface to obtain signals for displaying and recording in real time. The structure of NI MyDAQ is as figure 2 and figure 3 is the outside look of simulation platform.
Analog Input:

2 channels, 200kS/s, 16-bit

Analog Output:

2 channels, 200kS/s, 16-bit

$3.5 \mathrm{~mm}$ stereo audio jacks

Digital I/0: 8 LVTTL lines

Counter: 1 counter/timer

Integrated DMM: $V, A$, Ohm

Power Supply: $+5 \mathrm{~V},+/-15 \mathrm{~V}$

Screwterm + mass term option

Bus Powered (USB) operation

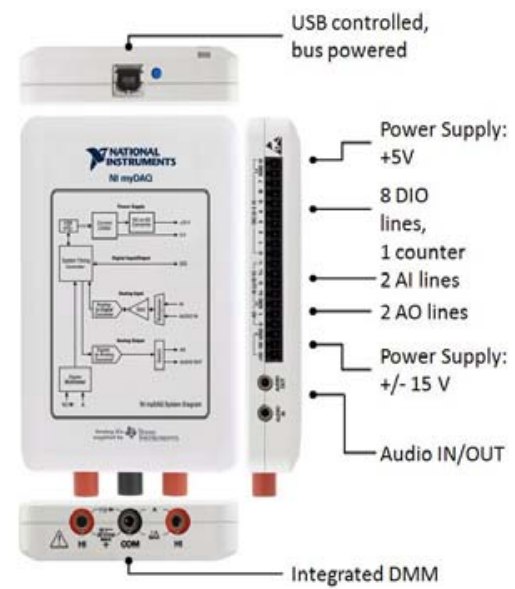

FIGURE II. THE OUTSIDE LOOK OF NI MYDAQ.

The system of myquake as figure 3: (1)Simulation Earthquake Platform of Myquake. (2) Power Supply. (3)Three-Axis Accelerometer. (4)Myquake Control Board. (5) NI MyDAQ.

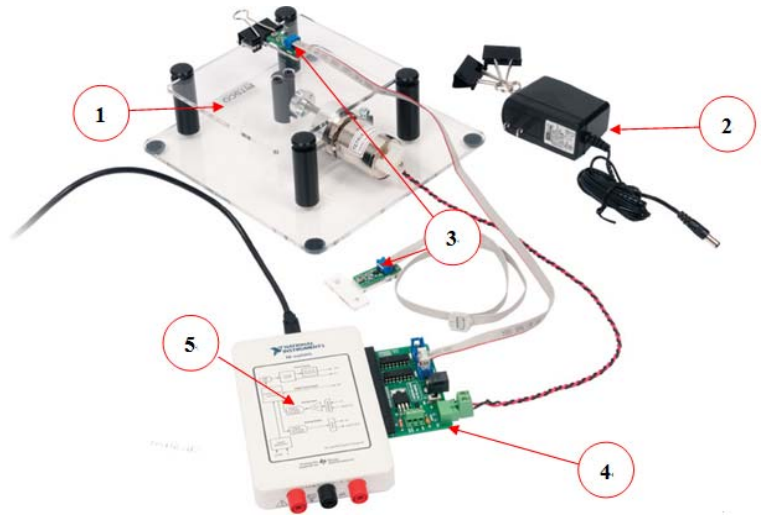

FIGURE III. THE EARTHQUAKE SIMULATION PLATFORM.

The Software of this paper uses LabVIEW as control simulation system. The software make the simulation system is low cost, strong data analyzing and fast processing. This study is in real-time to record the $\mathrm{p}$ wave and display in the LabVIEW.

The module channel and resolution is as table 2 .

TABLE II. THE MODULE CHANNEL AND RESOLUTION TABLE.

\begin{tabular}{|c|c|c|c|c|c|c|c|c|}
\hline & \multicolumn{8}{|c|}{ DIO } \\
\hline Accel_A & 0 & 1 & 2 & 3 & 4 & 5 & 6 & 7 \\
\hline \multirow{3}{*}{$\begin{array}{l}\mathrm{CHX} \\
\mathrm{CHY} \\
\mathrm{CHZ}\end{array}$} & 1 & 0 & $\mathrm{G}$ & $\mathrm{X}$ & $\mathrm{X}$ & $\mathrm{X}$ & $\mathrm{X}$ & 1 \\
\hline & 0 & 1 & G & $\mathrm{X}$ & $\mathrm{X}$ & $\mathrm{X}$ & $\mathrm{X}$ & 1 \\
\hline & 1 & 1 & $\mathrm{G}$ & $\mathrm{X}$ & $\mathrm{X}$ & $\mathrm{X}$ & $\mathrm{X}$ & 1 \\
\hline Accel B & 0 & 1 & 2 & 3 & 4 & 5 & 6 & 7 \\
\hline \multirow{3}{*}{$\begin{array}{l}\mathrm{CHX} \\
\mathrm{CHY} \\
\mathrm{CHZ}\end{array}$} & $\mathrm{X}$ & $\mathrm{X}$ & $\mathrm{X}$ & $\mathrm{X}$ & 1 & 0 & $\mathrm{G}$ & 1 \\
\hline & $\bar{X}$ & $\mathrm{X}$ & $\mathrm{X}$ & $\mathrm{X}$ & 0 & 1 & $\mathrm{G}$ & 1 \\
\hline & $\mathrm{X}$ & $\mathrm{X}$ & $\mathrm{X}$ & $\mathrm{X}$ & 1 & 1 & G & 1 \\
\hline \multicolumn{4}{|l|}{$\begin{array}{l}\mathrm{G}=0+/-1.5 \mathrm{~g} \\
\mathrm{G}=1+/-6 \mathrm{~g} \\
\mathrm{X}=\text { Don't Care }\end{array}$} & \multicolumn{4}{|c|}{ Motor Drive } & \\
\hline
\end{tabular}


The front panel and block diagram of system as figure 4(a) and figure 4(b): (1)module channel setup(2) motor control \%full scale setup (3) record the p wave and display (4) module channel and resolution setup (5)the signal of $p$ wave to filter and record and display (6) motor control \%full scale setup program

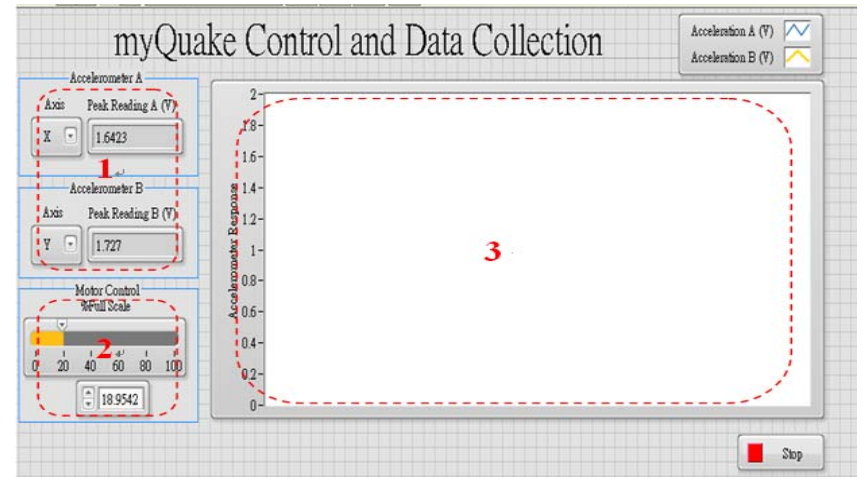

FIGURE IV. FRONT PANEL OF SYSTEM.
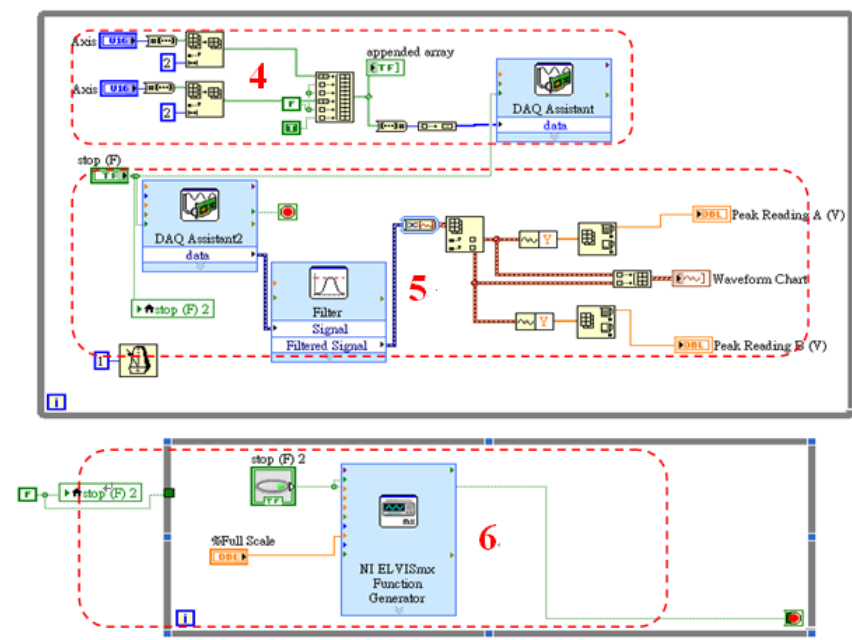

FIGURE V. BLOCK DIAGRAM OF SYSTEM.

\section{III.EXPERIMENTAL AND MEASUREMENTS}

Figure 5 is the measuring positions of Accelerometer " $A$ " and Accelerometer "B".

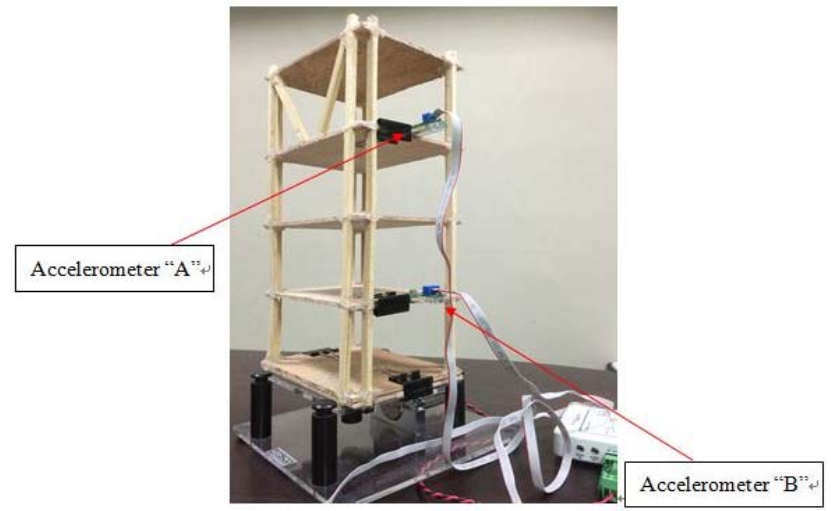

FIGURE VI. MEASUREMENT POSITIONS OF ACCELEROMETERS.
In Figure 6, as g-range $=1.5 \mathrm{~g}$ and measures the $\mathrm{p}$-wave data of $\mathrm{x}$-axis, $\mathrm{y}$-axis and $\mathrm{z}$-axis by adjusting Motor Control \%Full Scale to 100. Figure 6(a), figure 6(b) and figure 6(a) are Motor Control \%Full Scale=100. From experimental results, we can see the Accelerometer measuring amplitude of acceleration is larger, so if earthquake was happened, the bigger impact in the higher building than the lower building.

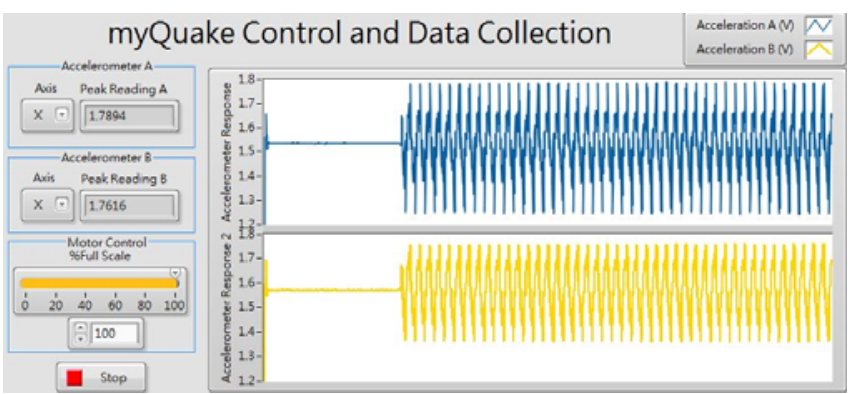

FIGURE VII. THE P-WAVE DATA OF X-AXIS WHEN THE MOTOR CONTROL \%FULL SCALE $=100$.

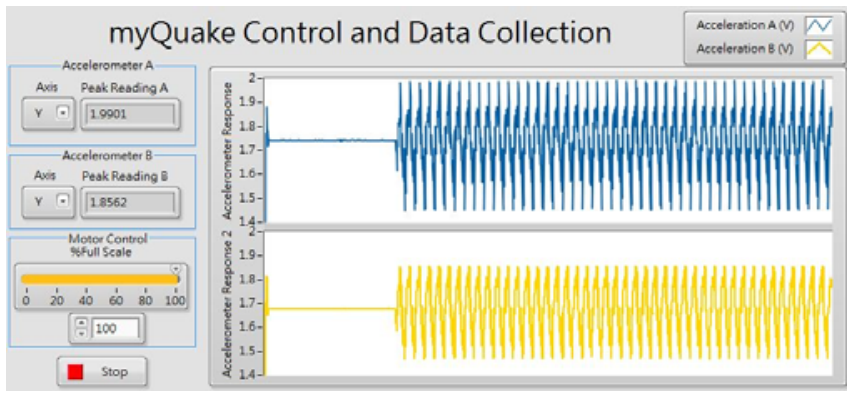

FIGURE VIII. THE P-WAVE DATA OF X-AXIS WHEN THE MOTOR CONTROL \%FULL SCALE $=100$.

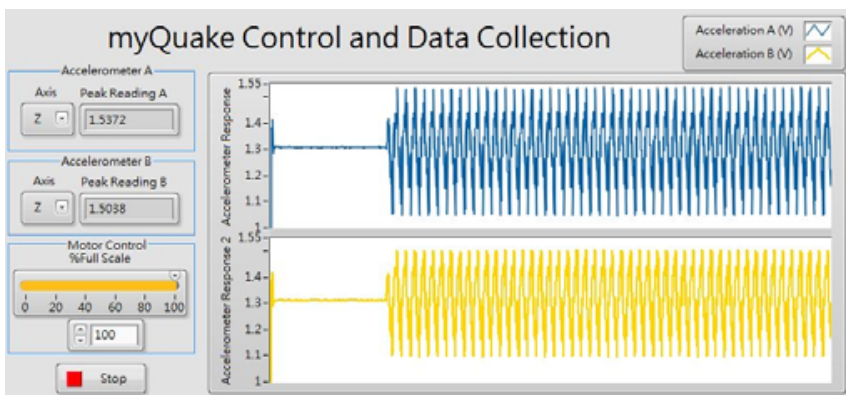

FIGURE IX. THE P-WAVE DATA OF Z-AXIS WHEN THE MOTOR CONTROL \%FULL SCALE $=100$.

\section{IV.RESULT}

This paper presents an industry-oriented simulation earthquake system platform by applying virtual instrumentation that can measure the $p$ wave. When concerned with platform, earthquake simulation system possesses instant data measurement acquisition and also able to save data for further processing and application. In earthquake simulation system design, programmable feature, equipment integration, control applications, cost, function and maintenance are all more efficient.

In this article, the labview platform is used to develop an earthquake simulation system platform. Compared with using 
other software, this graphical design tool is more friendly and powerful for users. The programmable features allow users to adjust the measurement function any time, any where.

This developed platform will be an effective teaching aid for training students in learning earthquake simulation system. This research work integrates basic technology, sensor and measurement device applications, advanced technology, virtual instrument into industry-oriented earthquake simulation system technology.

\section{ACKNOWLEDGEMENT}

This study was funded by a grant provided by the ministry of science and technology, Taiwan, under the grant number MOST 103-2511-S-018-016.

\section{REFERENCE}

[1] FAN Shian-Yi, LI Jau-Rong, CHUANG Chin-wen, Research and implementation of servo control of seismic platform, International Conference on Automatic Control and Artificial Intelligence, pp. 1670-1673, 2012.

[2] Cherian, C.M., Jayaraj, N., Vaidyanathan, S.G., Artificially Intelligent Tsunami Early Warning System, 12th International Conference on Computer Modeling and Simulation (UKSim), pp. 39-44, 2010.

[3] Hosokawa, M., Byeong-Pyo Jeong, Takizawa, O., Earthquake Intensity Estimation and Damage Detection Using Remote Sending Data for Global Rescue Operations, Geoscience and Remote Sensing Symposium, pp. II-420 - II-423, 2009.

[4] Boerner,W.-M., Implementation of Differential Repeat-pass SAR Interferometry for the Search for Earthquake recursory Land-cover Deformation in Taiwan, International Conference on Geoscience and Remote Sensing Symposium, pp. 497-500, 2006.

[5] Zhong Zhihuan, Yu Junjing, First International Symposium on Uncertainty Modeling and Analysis, pp. 173-176, 1990.

[6] Chi-Jan Huang, Che-hao Chang, Kuan-Yung Chang, Uncertainty propagation of Earthquake Loss Estimation System on the early seismic damage evaluation, 17th International Conference on Geoinformatics, pp. 1-6, 2009.

[7] Zhang Zhang, Jiang HuiLan, Zhang HuiJian, Wang JingPeng, Active power filter design and simulation by combining LabVIEW and Simulink, International Conference on Advanced Power System Automation and Protection (APAP), pp. 1104-1109, 2011.

[8] Xiang Xuejun, Xia Ping, Yang Sheng, Liu Ping, Real-time Digital Simulation of Control System with LabVIEW Simulation Interface Toolkit, Control Conference on Chinese, pp. 318-322, 2007.

[9] Turley, P., Wright, M., Developing Engine Test Software in LabVIEW, IEEE Autotestcon Proceedings , pp. 575-579, 1997.

[10] Swain, N.K.,Anderson, J.A., Ajit Singh., Swain, M., Fulton, M., Garrett, J., Tucker, O., Remote data acquisition, control and analysis using LabVIEW front panel and real time engine, Control and Analysis using LabVIEW Front Panel and Real Time Engine, SoutheastCon , pp. 1-6, 2003. 